\title{
Amyand Hernia: A Literature Review of the Diagnosis and Management of the Rare Presentation of the Wandering Appendix
}

\section{S Ikram*, A Kaleem and SM Ahmad}

Northern Lincolnshire and Goole Hospitals, NHS Foundation Trust, Scunthorpe, United Kingdom

${ }^{*}$ Corresponding author: S Ikram, General Surgery, Northern Lincolnshire and Goole Hospitals, NHS Foundation Trust, Scunthorpe, United Kingdom, Tel: +44 1724 282282; E-mail: drsikram@hotmail.com

Received date: January 14, 2018; Accepted date: January 24, 2018; Published date: January 31, 2018

Citation: S Ikram, A Kaleem, SM Ahmad (2018) Amyand Hernia: A Literature Review of the Diagnosis and Management of the Rare Presentation of the Wandering Appendix. J Rare Disord Diagn Ther. Vol. 4 No. 1: 1.

Copyright: (c) $2018 \mathrm{~S} \mathrm{Ikram}$, et al. This is an open-access article distributed under the terms of the Creative Commons Attribution License, which permits unrestricted use, distribution, and reproduction in any medium, provided the original author and source are credited.

\begin{abstract}
A hernia is defined as a protrusion of an organ or its fascia through a sac of its containing cavity. When an appendix is contained within such a sac, the hernia is termed an Amyand Hernia and it forms an extremely rare presentation. Commonly seen in the young male patient, this type of hernia like all others can undergo strangulation leading to complications including appendicitis with or without perforation. Management as described in literature will depend on clinical presentation of the hernia and the appendix within, however it should be catered to each patient individually. We describe below the diagnosis and management of such hernias as presented in the literature.
\end{abstract}

Keywords: Amyand hernia; Appendix; Appendectomy

\section{Background}

Hernia and appendicitis form two of the most frequently encountered surgical pathologies. These occurring together however a rare presentation is termed an Amyand Hernia. Mostly discovered intra-operatively, these hernias are now being frequently diagnosed pre-operatively with Ultrasounds and CT scans. Surgical treatment depends on the condition of the appendix but generally involves appendectomy with some form of hernia repair, with or without mesh based on surgical site contamination risk and surgeon's assessments and expertise. Even though the treatment options have been universalized with Lasonoff and Basson's classification, more trials are needed to ascertain its effectiveness and further provide with treatment options which can be catered to each patient individually.

\section{Literature Review}

The presence of a vermiform appendix contained within a hernia sac was first reported by Claudius Amyand, a French born English Surgeon in 1735 in London, who operated on a 11 year old boy for an inguinal hernia repair and found an inflamed perforated appendix in the sac [1-3]. The hernia hence received its name after this pioneer surgeon. Hernia with all its types form an extremely common presentation in the province of surgery, an Amyand Hernia however, still remains one of its very rare varieties. The incidence reported in literature varies between $0.19-1.7 \%$ [1]. It is commonly seen in young male patients, however, age ranges from 3 weeks to 92 years have been highlighted in the literature [1,2]. Although common in the inguinal hernia, the appendix has been reported to be found in incisional, obturator and umbilical hernias [2]. The presence of appendicitis within the sac is attributed to compression at the neck of the sac with resulting ischaemia and infection $[3,4]$ which is an even rarer presentation accounting for $0.1 \%$ of all inguinal hernias $[2,3,5]$. Preoperative diagnosis is often a rare occurrence due to the fact that investigations are not usually ordered for a clinically diagnosed hernia and as such the diagnosis is made intra operatively in vast majority of times, however more recently, ultrasound and $\mathrm{CT}$ scanning has shown most promise in picking up these kind of hernias in the preoperative period where they are ordered to diagnose or rule out abdominal pathology $[1,2,5]$. The management of such a hernia is dictated by the condition of the appendix within. Approach for surgery should be based on each clinical picture. Appendectomy through herniotomy with primary hernia repair will be the ideal treatment for such hernias in contrast to lower midline laparotomy which should be reserved for cases where complications are suspected [1]. Primary repair of the hernia with a mesh in the absence of appendicitis and avoiding mesh placement for hernia repair in presence of appendicular complications, seems to be a consensus seen there and again in literature review [1-4]. One study did highlight that use of mesh should not be determined by the condition of the appendix, provided intra operatively the cavity and incision site is thoroughly irrigated, drains placed and post operatively the patient remains on antibiotics [1]. The decision ultimately will depend based on many clinical aspects being kept in mind but as a general recommendation, literature review highlighted a classification system along with management 
options outlined by Losanoff and Basson, as described in (Table 1) [1-5].

Table 1: Classification of Amyand's hernias after Losanoff and Basson.

\begin{tabular}{|c|l|c|}
\hline Classification & Description & Surgical Management \\
\hline Type 1 & Normal appendix within an inguinal hernia & $\begin{array}{l}\text { Hernia reduction, mesh repair, appendectomy in } \\
\text { young patients }\end{array}$ \\
\hline Type 2 & $\begin{array}{l}\text { Acute appendicitis within an inguinal hernia, no } \\
\text { abdominal sepsis }\end{array}$ & $\begin{array}{l}\text { Appendectomy endogenous repair of hernia, no mesh } \\
\text { through hernia, primary }\end{array}$ \\
\hline Type 3 & $\begin{array}{l}\text { Acute appendicitis within an inguinal hernia, } \\
\text { abdominal wall or peritoneal sepsis }\end{array}$ & $\begin{array}{l}\text { Laparotomy, appendectomy, primary repair of } \\
\text { hernia, no mesh }\end{array}$ \\
\hline Type 4 & $\begin{array}{l}\text { Acute appendicitis within an inguinal hernia, related } \\
\text { or unrelated abdominal pathology }\end{array}$ & $\begin{array}{l}\text { Manage as types } 1 \text { to } 3 \text { hernia, investigate or treat } \\
\text { second pathology as appropriate }\end{array}$ \\
\hline
\end{tabular}

Where appendix is found to be inflamed, suppurative or perforated, a Shouldice repair is recommended based on its low recurrence rate [4]. More and more of such hernias are being managed via a laparoscopic approach, with conversion to open in the presence of complications [1].

With the development of biological and more advanced mesh for hernia repair, more studies and trials are needed to direct treatment of such hernias in the presence of complications, [3] enabling use of mesh in unfavorable conditions to reduce recurrence without added risk of infection.

\section{References}

1. Ivashchuk G, Cesmebasi A, Sorenson EP, Blaak C, Tubbs SR, et al. (2014) Amyand's hernia: A review. Med Sci Monit 20: 140-146.
2. Green L, Gutwein LG (2013) Amyand's hernia: a rare inguinal hernia. J Surg Case 2013: rjt043.

3. Psarras K, Lalountas M, Baltatzis M, Pavlidis E, Tsitlakidis A, et al. (2011) Amyand's hernia-a vermiform appendix presenting in an inguinal hernia: a case series. J Med Case Rep 5: 463.

4. Morales-Cárdenas A, Ploneda-Valencia CF, Sainz- Escárrega VH, Hernández-Campos AC, Navarro-Muñiz E, et al. (2015) Amyand hernia: Case report and review of the literature. Ann Med Surgery 4: 113-115.

5. Islam S, Hosein D, Bheem V, Naraynsingh V (2015) The appendix and the inguinal canal: Amyand's hernia a case report. Int J Case Rep Images 6: 636-639. 